\title{
Mathematical Modelling of Non-Isothermal Moisture Transfer and Rheological Behavior in Cappilary-Porous Materials with Fractal Structure During Drying
}

\author{
Yaroslav Sokolowskyi ${ }^{1} \&$ Volodymyr Shymanskyi ${ }^{1}$ \\ ${ }^{1}$ Department of information technology, National Forestry University of Ukraine, General Chuprynka Str. 103, \\ Lviv, Ukraine \\ Correspondence: Volodymyr Shymanskyi, Department of information technology, National Forestry University \\ of Ukraine, General Chuprynka Str. 103, Lviv, Ukraine. E-mail: vshymanskiy@gmail.com
}

Received: July 27, 2014

Accepted: July 30, 2014

Online Published: October 17, 2014

doi:10.5539/cis.v7n4p111

URL: http://dx.doi.org/10.5539/cis.v7n4p111

\begin{abstract}
The mathematical model of the distribution of deformation-relaxation and heat-mass fields in capillary-porous materials with fractal structure in the process of drying wood is regarded in the article. We used differential equations in partial derivatives of fractional order in description of this model. To describe the creep of wood fractional exponential Rabotnov's function was used. The numerical solution of the problem for different values of the fractional derivative was obtained by difference method. The comparative characterezation beetwen the use of mathematical tools of differential equations of fractional order and traditional methods for finding the numerical solution of this problem was conducted.
\end{abstract}

Keywords: fractional order of a derivative, fractal, non-isothermal moisture transfer, capillary-porous materials, numerical method, deformation-relaxation field

\section{Introduction}

Nowadays there is an urgent research problem of creating adequate mathematical models of distributing deformation-relaxation and temperature-humiditive fields in drying materials. The solution of this problem is complicated by the fact that wood is characterized by high hydrophobicity, great variability of physical and mechanical properties of its structure in the directions of anisotropy. Environments characterized by such properties are called environments with fractal structure. Thus not only the presence of physical and mathematical models adequate the real processes but also the choice of efficient numerical method for its implementation is actual for analyzing the process of wood drying.

Mathematical model of non-isothermal moisture transfer in wood during drying was described by G.S. Shubin, P.V. Bilej, Ya.I. Sokolowskyi, P.S. Syergowskyi, J.-G. Salin. Taking into account the complexity of the wood material structure they regarded different ways of constructing mathematical models allowing to simplify the task through reducing the dimension of the problem, the constancy of temperature and moisture fields, ignoring their anisotropy.

A significant contribution to the study of the stress-strain state in wood during drying was made by B.N. Uholjev, Ya.I. Sokolowskyi, B.P. Poberejko, S. Svensson, T. Toratti, M. Lawniczak. Various models and corresponding rheological equations for modeling deformation of the sample with a narrow range of variation of temperature and moisture characteristics were proposed by them. Nevertheless, on the base of their works we can conclude that the construction of the general equation of the rheological state of wood during drying is rather a difficult and not completely solved problem.

To describe the rheological behavior of the environment in the linear region familiar rheological models were used. The main drawback of these models is that the material properties such as "memory", the complex nature of spatial correlations and the effects of self-organization were not taken into consideration by them. All these properties are considered in the process of formation the fractal rheological model by using the mathematical tool of integration and differentiation of fractional order in our investigation.

Thus, the fractal mathematical model of non-isothermal moisture transfer in capillary-porous materials during 
drying described by a system of differential equations with partial derivatives of fractional order and the corresponding initial and boundary conditions was constructed. For simulating the rheological behavior of wood during drying the fractal patterns formed by sequential or parallel connection of the elastic and fractal element were used.

\section{Production of a Problem}

The process of drying wood can be described by a mathematical model consisting of a system of differential equations with partial derivatives of fractional order:

$$
\left\{\begin{array}{l}
c \rho \frac{\partial^{\alpha} T}{\partial \tau^{\alpha}}=\lambda \Delta T+\varepsilon \rho_{0} r \frac{\partial^{\alpha} U}{\partial \tau^{\alpha}} \\
\frac{\partial^{\alpha} U}{\partial \tau^{\alpha}}=a \Delta U+a \delta \Delta T
\end{array}\right.
$$

and appropriate initial conditions

$$
\left.T\right|_{\tau=0}=T_{0}(x) ;\left.\quad U\right|_{\tau=0}=U_{0}(x)
$$

and boundary conditions of 3rd kind

$$
\left\{\begin{array}{l}
\left.\lambda_{1} \frac{\partial T}{\partial x}\right|_{x=l_{1}}+\rho_{0}(1-\varepsilon) \beta_{1}\left(\left.U\right|_{x=l_{1}}-U_{P}\right)=\alpha_{1}\left(\left.T\right|_{x=l_{1}}-t_{c}\right) \\
\left.\lambda_{2} \frac{\partial T}{\partial y}\right|_{y=l_{2}}+\rho_{0}(1-\varepsilon) \beta_{2}\left(\left.U\right|_{y=l_{2}}-U_{P}\right)=\alpha_{2}\left(\left.T\right|_{y=l_{2}}-t_{c}\right) \\
\left.a_{1} \delta \frac{\partial T}{\partial x}\right|_{x=l_{1}}+\left.a_{1} \frac{\partial U}{\partial x}\right|_{x=l_{1}}=\beta_{1}\left(U_{P}-U_{x=l_{1}}\right) \\
\left.a_{2} \delta \frac{\partial T}{\partial y}\right|_{y=l_{2}}+\left.a_{2} \frac{\partial U}{\partial y}\right|_{y=l_{2}}=\beta_{2}\left(U_{P}-U_{y=l_{2}}\right) \\
\left\{\begin{array}{l}
\left.\frac{\partial T}{\partial x}\right|_{x=0}=0 ; \\
\left.\frac{\partial T}{\partial y}\right|_{y=0}=0 ; \\
\left.a_{1} \delta \frac{\partial T}{\partial x}\right|_{x=0}+\left.a_{1} \frac{\partial U}{\partial x}\right|_{x=0}=0 \\
\left.a_{2} \delta \frac{\partial T}{\partial y}\right|_{y=0}+\left.a_{2} \frac{\partial U}{\partial y}\right|_{y=0}=0
\end{array}\right.
\end{array}\right.
$$

where $U$ - humidity; $T$ - temperature; $\tau$ - time; $\lambda_{i}(T, U)$ - coefficients of thermal conductivity; $a_{i}(T, U)$ - coefficients of humidity conductivity ; $n$ - outside normal; $U_{P}\left(t_{c}, \varphi\right)$ - the equilibrium humidity, which is a function of ambient temperature $t_{c}$ and relative humidity of the environment $\varphi$; $c(T, U)$ - thermal capacity; $\rho(U)$ - density; $\rho_{0}$ - base density; $\varepsilon$ - phase transition coefficient; $v$ - the speed of drying agent; $r$ - heat of vaporization; $\alpha_{i}\left(t_{c}, v\right)$ - heat transfer coefficient; $\beta\left(t_{c}, \varphi, v\right)$ moisture transfer coefficient; $\delta(T, U)$ - thermogradient coefficient; $\alpha$ - fractional derivative order (describing the part of the channels open for flow).

Replacing real materials with their idealized models is based on the fact that some properties of these materials are realized in the majority of cases most clearly. Rejecting all the unimportant properties we can construct an ideal model with dominative characteristics of real materials. In particular, taking into account only the properties of elasticity and viscosity we can construct simple rheological models used in the researches based on the viscous-elastic theory. These patterns are formed by sequential or parallel connection of the elastic and viscous elements. The behavior of the elastic element is based on Hooke's law and the behavior of the viscous element is based on Newton's law of viscosity. 
Constructed in this way the simple rheological models will not include such material properties as "memory", complex nature of spatial correlations, and effects of self-organization that characterize wood. That's why we suggest to use the mathematical tool of integration and differentiation of fractional order for description of Newton's law of viscosity, allowing to take into account the above mentioned material properties of wood. Thus using this mathematical tool to describe the viscous properties of the element allows to create a new item, that is called a fractal element. This element has all the properties of the viscous element and allows to take into account the effects of "memory", complex nature of spatial correlations and self-organization of the material.

The Kelvin's fractal model characterized by serial connection of Voigt's fractal model (parallel connection of elastic and fractal element) and an elastic element was constructed by us.

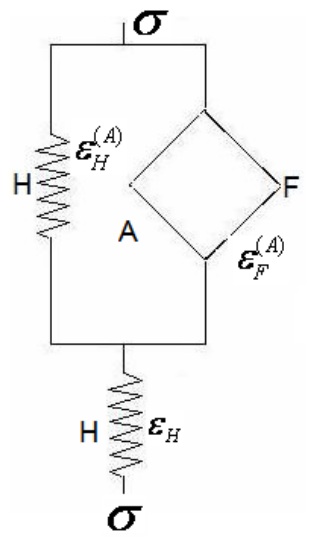

Figure 1. Kelvin's fractal model

$$
\begin{aligned}
& \left\{\begin{array}{l}
\sigma^{(A)}=\sigma_{H}^{(A)}+\sigma_{F}^{(A)} \\
\varepsilon^{(A)}=\varepsilon_{H}^{(A)}=\varepsilon_{F}^{(A)} \\
\sigma_{H}^{(A)}=E_{1} \varepsilon_{H}^{(A)} \\
\sigma_{F}^{(A)}=E_{1} \eta^{\alpha} D^{\alpha} \varepsilon_{F}^{(A)} \\
\sigma^{(A)}=E_{1} \varepsilon_{H}^{(A)}+E_{1} \eta^{\alpha} D^{\alpha} \varepsilon_{F}^{(A)}
\end{array}\right. \\
& \left\{\begin{array}{l}
\sigma=\sigma^{(A)}=\sigma^{(H)} \\
\varepsilon=\varepsilon^{(A)}+\varepsilon^{(H)} \\
\sigma^{(H)}=E_{2} \varepsilon^{(H)} \\
\varepsilon^{(H)}=\frac{1}{E_{2}} \sigma^{(H)} \\
\sigma=E_{1} \varepsilon_{H}^{(A)}+E_{1} \eta^{\alpha} D^{\alpha} \varepsilon_{F}^{(A)}=E_{2} \varepsilon^{(H)}
\end{array}\right.
\end{aligned}
$$

Thus, the relationship between stress $\sigma$ and deformation $\varepsilon$ can be written as (7). Here $D^{\alpha} f$ is the operator of differentiation of fractional order.

$$
\sigma(t)+b D^{\alpha} \sigma(t)=\tilde{E}_{0} \varepsilon(t)+\tilde{E}_{1} D^{\alpha} \varepsilon(t)
$$

where, $\quad \tilde{E}_{1}=\frac{E_{1} E_{2} \eta_{0}^{\alpha}}{E_{1}+E_{2}}, \quad b=\frac{E_{1} \eta_{0}^{\alpha}}{E_{1}+E_{2}}, \quad \tilde{E}_{0}=\frac{E_{1} E_{2}}{E_{1}+E_{2}}$.

Relaxation function will be as follows: 


$$
R(t)=\frac{E_{1}}{b}\left(h(t)+\left(1-\frac{b E_{0}}{E_{1}}\right) E_{\alpha}\left(-\frac{t^{\alpha}}{b}\right)\right)
$$

Free energy is determined as:

$$
\Psi=-\frac{C_{p}}{2 T_{0}} \Delta T^{2}+\frac{2}{2 R(0)}\left[\int_{0}^{t} \frac{\tilde{E}_{1}}{b}\left(h(\tau)+\left(1-\frac{b \tilde{E}_{0}}{\tilde{E}_{1}}\right) E_{\alpha}\left(-\frac{t^{\alpha}}{b}\right)\right) d \varepsilon_{T}(\tau)\right]^{2}
$$

Accordingly, the energy dissipation function will be as follows:

$$
\begin{aligned}
W^{*}=-\frac{1}{R(0)} \int_{0}^{t^{\prime}} \int_{0}^{t^{\prime}} & {\left[\frac{\tilde{E}_{1}}{b}\left(h\left(t^{\prime}-\tau_{1}\right)+\left(1-\frac{b E_{0}}{E_{1}}\right) E_{\alpha}\left(-\frac{1}{b}\left(t^{\prime}-\tau_{1}\right)\right)\right) \times\right.} \\
\times & \left.\times \frac{\tilde{E}_{1}}{b}\left(\delta\left(t^{\prime}-\tau_{2}\right)-\left(\frac{1}{b}-\frac{\tilde{E}_{0}}{\tilde{E}_{1}}\right) \ni_{\alpha-1}\left(-\frac{1}{b}, t^{\prime}-\tau_{2}\right)\right)\right] d \varepsilon_{T}\left(\tau_{1}\right) d \varepsilon_{T}\left(\tau_{2}\right)
\end{aligned}
$$

To simulate the stress-deformable state of wood components of the displacement vector $u=\left(u_{1}, u_{2}\right)^{T}$ should be found, which satisfies the equation of equilibrium

$$
B^{T} \sigma=0
$$

Boundary conditions (which take into account the symmetry of the problem area) are the following:

$$
\left.u_{i}\right|_{x_{i}=0}=0 ;\left.\quad \quad \sigma_{i i}\right|_{x_{i}=l_{i}}=0
$$

The notations are introduced here $\sigma=\left(\sigma_{11}, \sigma_{22}, \sigma_{12}\right)^{T}$ - stress component vector, $B$ - matrix of differential operators

$$
B^{T}=\left[\begin{array}{ccc}
\frac{\partial}{\partial x_{1}} & 0 & \frac{\partial}{\partial x_{2}} \\
0 & \frac{\partial}{\partial x_{2}} & \frac{\partial}{\partial x_{1}}
\end{array}\right]
$$

The correlation between displacements and vector of deformations $\varepsilon=\left(\varepsilon_{11}, \varepsilon_{22}, \varepsilon_{12}\right)^{T}$ can be shown as

$$
\varepsilon=B u
$$

The relationship between stress and strain components can be written using integral equations:

$$
\begin{aligned}
& \varepsilon(t)=\frac{\sigma(t)}{E}+\frac{1}{E} \int_{0}^{t} \Pi(t, \tau) \sigma(t) d \tau^{\alpha} ; \\
& \sigma(t)=E \varepsilon(t)+E \int_{0}^{t} R(t, \tau) \varepsilon(t) d \tau^{\alpha}
\end{aligned}
$$

where $\Pi(t, \tau)$ - creep core, $R(t, \tau)$ - relaxation core.

\section{The Numerical Method for Solving Differential Equations of Derivatives with Fractional Order}

We define the derivative of fractional order $\alpha$ in the interval $\left[\tau^{n} ; \tau^{n+1}\right]$ in the sense of Riemann-Liouville problem:

$$
\left.\frac{\partial^{\alpha} f}{\partial t^{\alpha}}\right|_{\tau^{n}}=\frac{1}{\Gamma(1-\alpha)}\left[\frac{u\left(\tau^{n}\right)}{\left(\tau^{n+1}-\tau^{n}\right)^{\alpha}}+\int_{\tau^{n}}^{\tau^{n+1}} \frac{u^{\prime}(\xi)}{\left(\tau^{n+1}-\tau^{n}\right)^{\alpha}} d \xi\right]
$$

Where $\Gamma(\alpha)=\int_{0}^{\infty} x^{\alpha-1} e^{-x} d x$ - gamma function.

$\mathrm{n}$ - index of the corresponding time interval $\left\lfloor\tau^{n} ; \tau^{n+1}\right\rfloor$.

We write the finite-difference approximation of the derivative of first order $f^{\prime}(\xi)$ in the interval $\left[\tau^{n} ; \tau^{n+1}\right]$ in the finite differences form: 


$$
\frac{d f}{d \tau} \approx \frac{u^{n+1}-u^{n}}{\Delta \tau} \quad\left(\Delta \tau=\tau^{n+1}-\tau^{n}\right)
$$

Thus, the approximation of derivative of fractional order $\alpha$ on the interval $\left[\tau^{n} ; \tau^{n+1}\right]$ is defined as follows:

$$
\left.\frac{\partial^{\alpha} f}{\partial \tau^{\alpha}}\right|_{\tau^{n}}=\frac{u^{n+1}-\alpha u^{n}}{\Gamma(1-\alpha)(1-\alpha) \Delta \tau^{\alpha}}
$$

For finding the numerical solution of the problem (1) - (4) the predictor-corrector method was used. This method based on the finite-difference approximation (18). As a predictor the explicit difference scheme was used and as a corrector - the implicit.

\section{Results and Discussion}

To find the numerical values of temperature and moisture fields and the components of stress and strain tensors during drying materials with a fractal structure that include wood we determined the parameter of material fractality $\alpha$ by approximating the experimental data of wood creep obtained by taking into account all necessary requirements for conducting the experiment. It was found that this parameter depends on temperature, moisture content and species of wood.

Table 1. Parameter of wood fractality that depends on the species of wood and moisture content

\begin{tabular}{lccc}
\hline $\begin{array}{l}\text { moisture } \\
\text { wood }\end{array}$ & $12 \%$ & $24 \%$ & $40 \%$ \\
\hline pine & 0,8211 & 0,8254 & 0,8312 \\
birch & 0,8728 & 0,8781 & 0,8803 \\
beech & 0,9071 & 0,9088 & 0,9103 \\
oak & 0,9244 & 0,9255 & 0,9263 \\
\hline
\end{tabular}

Table 1 shows the value parameter of wood fractality that depends on the species of wood and moisture content. As it is seen from the results, increasing moisture content decreases the degree of wood fractality, it gets closer to 1.

Table 2. Parameter of the wood fractality that depends on the species of wood and temperature

\begin{tabular}{lccc}
\hline $\begin{array}{l}\text { temperature } \\
\text { wood }\end{array}$ & $40{ }^{\circ} \mathrm{C}$ & $60{ }^{\circ} \mathrm{C}$ & $80{ }^{\circ} \mathrm{C}$ \\
\hline pine & 0,8211 & 0,8392 & 0,8665 \\
birch & 0,8728 & 0,8841 & 0,8937 \\
beech & 0,9071 & 0,9196 & 0,9304 \\
oak & 0,9244 & 0,9367 & 0,9446 \\
\hline
\end{tabular}

Table 2 shows the parameter of the wood fractality that depends on the species of wood and temperature. As it is seen from the given results, increasing temperature decreases the wood fractality. The temperature of wood has much greater impact on the degree of wood fractality than the moisture content. Also, comparing the data of table 1 and table 2 we come to the conclusion that the fractality degree of softwood is higher than of hardwood.

The numerical calculations of the temperature and moisture fields and the components of stress and deformation tensors during drying materials with fractal structure were conducted. Oak was selected as the material, with the initial value of moisture content $u_{0}=0.4 \mathrm{~kg} / \mathrm{kg}$, temperature $T_{0}=40{ }^{\circ} \mathrm{C}$ and the environment temperature $t_{c}=70{ }^{\circ} \mathrm{C}$. The fractality parameter of this material with the given above values of temperature and moisture content was found by approximating the experimental data of oak creep. It equals $\alpha=0.9263$.

On Fig. 2 we see the distribution of temperature fields on the samples with different geometrical dimensions depending on the spatial coordinates after the first hour of drying. As a sample a bar of the sizes $\left[l_{1} \times l_{2}\right]$, was taken where $l_{1}$ and $l_{2}$ are the halves of the geometric dimensions. 


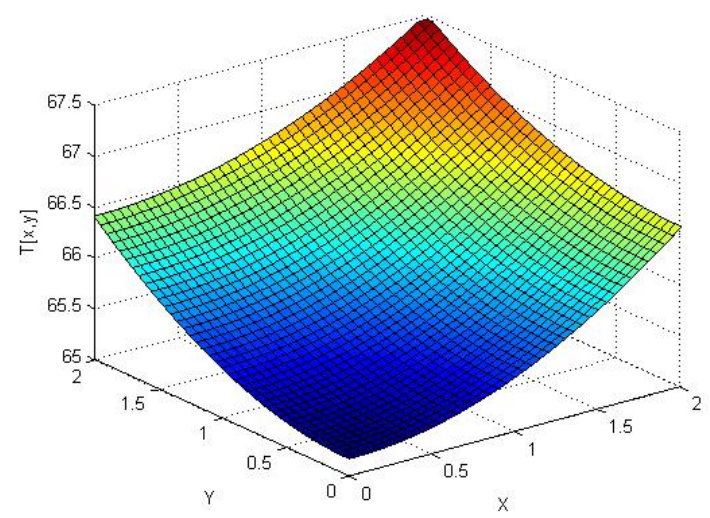

(a)

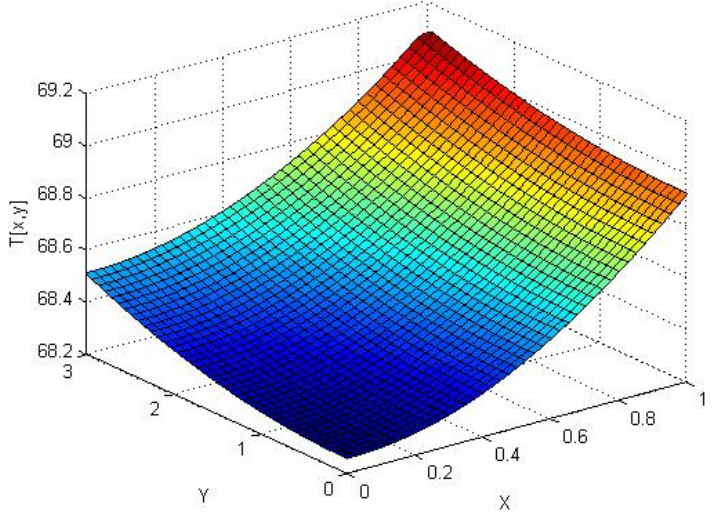

(c)

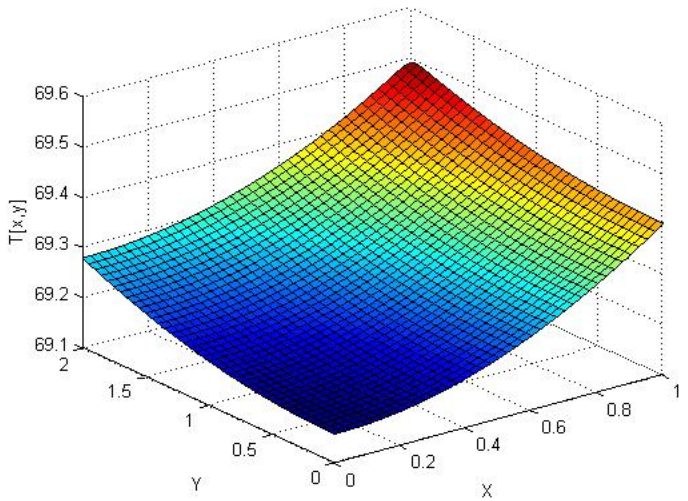

(b)

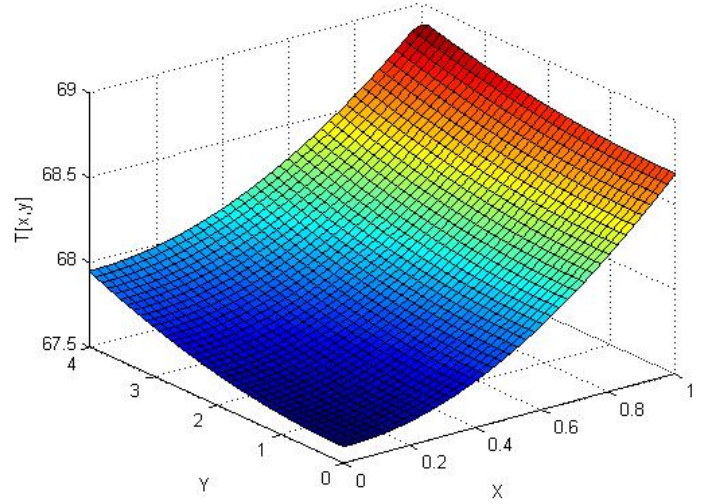

(d)

Figure 2. Distribution of temperature fields depending on the spatial coordinates and different geometric size of the sample: a) $\left[l_{1} \times l_{2}\right]=[2 ; 2]$; b) $\left[l_{1} \times l_{2}\right]=[1 ; 2]$; c) $\left[l_{1} \times l_{2}\right]=[1 ; 3]$; d) $\left[l_{1} \times l_{2}\right]=[1 ; 4]$

Figure 3 shows the distribution of moisture fields on sample with different geometrical dimensions depending on the spatial coordinates after the first hour of drying.

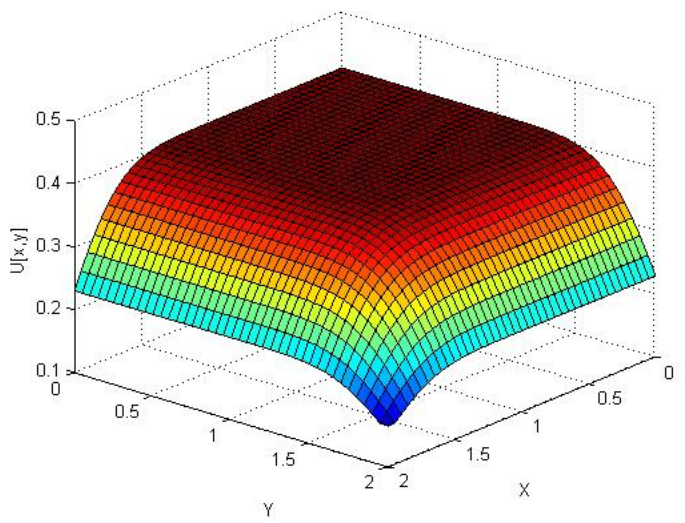

(a)

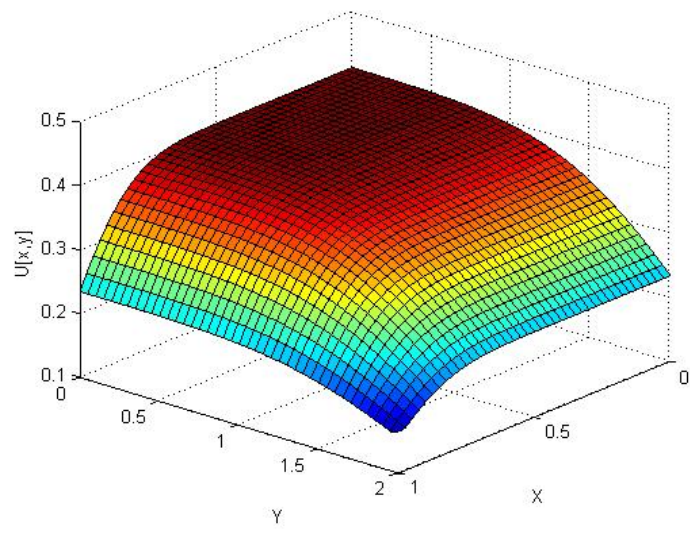

(b) 


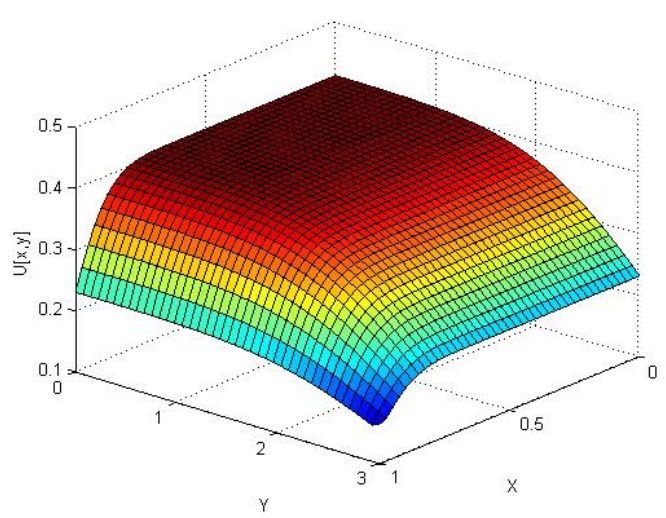

(c)

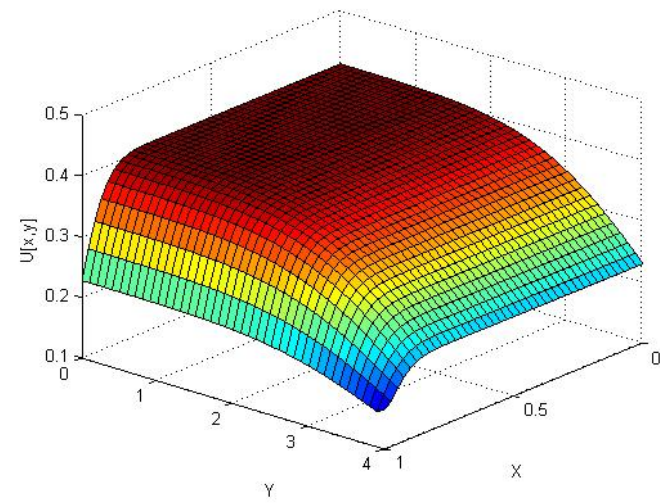

(d)

Figure 3. Distribution of moisture fields depending on the spatial coordinates and different geometric size of the sample: a) $\left[l_{1} \times l_{2}\right]=[2 ; 2]$; b) $\left[l_{1} \times l_{2}\right]=[1 ; 2] ;$ c) $\left[l_{1} \times l_{2}\right]=[1 ; 3]$; d) $\left[l_{1} \times l_{2}\right]=[1 ; 4]$

The received graphical results on Figure 2 and Figure 3 give us the possibility to analyze the numerical values of the process of heating and moisture transferring in an oak bar of specified sizes during drying. The temperature rises in the bar from the boundary to the centre progressively. With raising the temperature the process of moisture transferring in the direction from the boundary to the centre of the bar begins. These results are intuitively clear and correspond with the nature of the process of drying.

The objective of this paper is to show the degree of the influence of the material fractality on the non-isothermal process moisture transfer and viscous-elastic deformation. Let's analyze the numerical results and built on their base graphical dependences of the processes occurring in the material during drying without taking into consideration material fractality $(\alpha=1)$ and taking it into account $(0<\alpha<1)$.

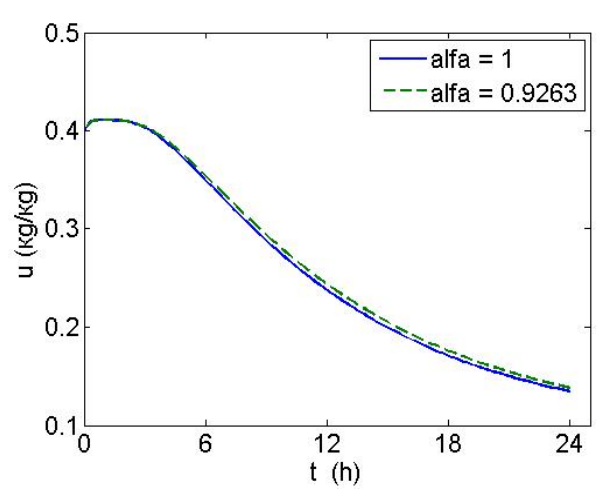

(a)

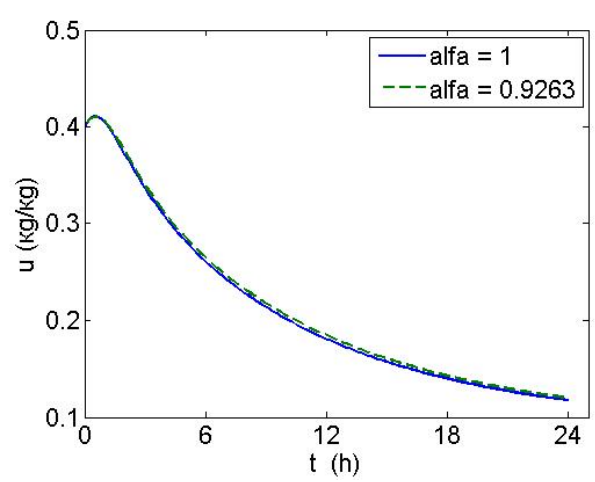

(b) 


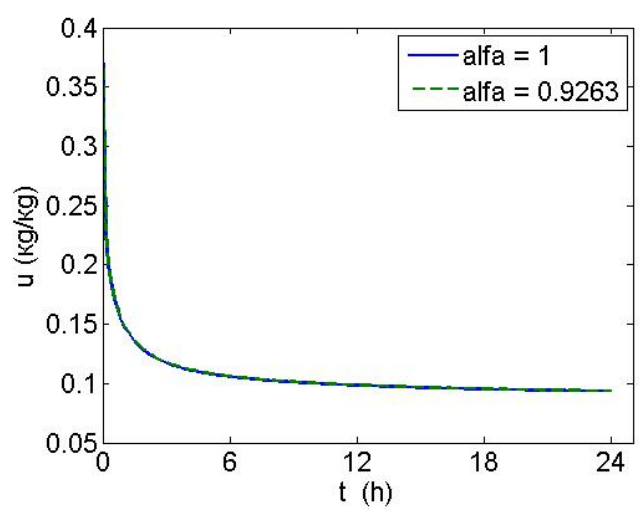

(c)

Figure 4. Distribution of moisture fields depending on the time in different geometric points of the sample: a)

$$
\left.A(0 ; 0) ; \mathrm{b}) B\left(l_{1} / 2 ; l_{2} / 2\right) ; \mathrm{c}\right) C\left(l_{1} ; l_{2}\right)
$$

Figure 4 shows the distribution of moisture in dependence on time during the first 24 hours of drying in the points: $A(0 ; 0)$ - the centre of the sample; $B\left(l_{1} / 2 ; l_{2} / 2\right)$ - the middle of the distance from the centre of the sample to its angular point; $C\left(l_{1} ; l_{2}\right)$ - the angular point of the rectangular bar. These graphic dependences allow us to estimate the influence of the material fractality on the moisture transfer process.

As it can be seen on figure 4 the humidity from the centre of the sample releases slower than from the closer to the boundary points. This fact fully corresponds with understanding the process of moisture transfer during drying. We take into consideration the fact that in fractal materials the moisture transfer process slows down. It is caused by the heterogeneous structure of the material of wood. The fact that the material fractality has a greater impact on the process in the centre of the sample than in the points closer to the boundary is obvious.

We can show the values of the components of stress and strain tensors in points $A(0 ; 0), B\left(l_{1} / 2 ; l_{2} / 2\right)$ and $C\left(l_{1} ; l_{2}\right)$ in dependence on time and the influence of material fractality.

In figure 5 we see the graphic dependences of the stress component $\sigma_{11}$ on time in different points of the bar cross-section.

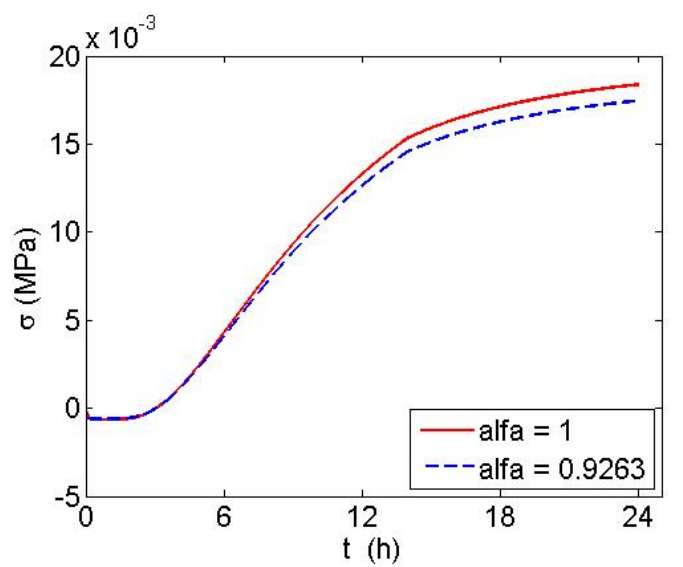

(a)

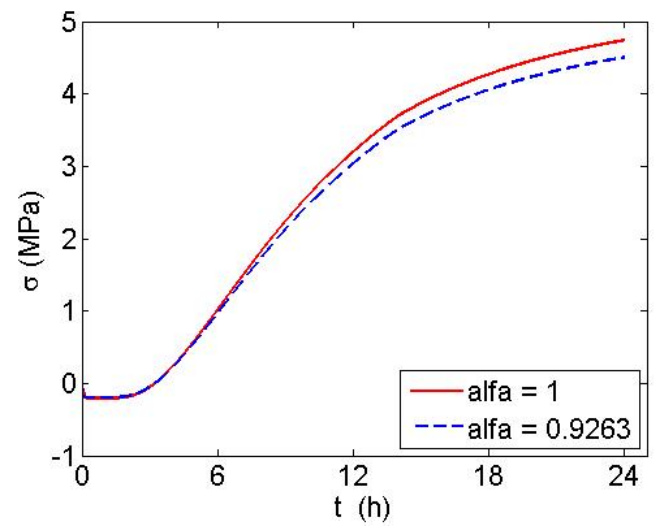

(b) 


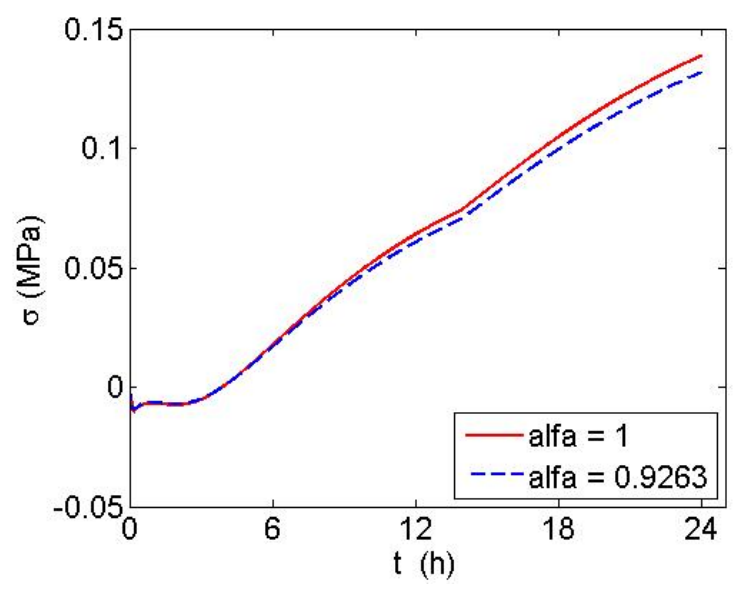

(c)

Figure 5. The value of stress components $\sigma_{11}$ depending on the time at different points in the cross-section of the bar: a) $A(0 ; 0)$; b) $B\left(l_{1} / 2 ; l_{2} / 2\right)$; c) $C\left(l_{1} ; l_{2}\right)$

Figure 6 shows the value of stress components $\sigma_{22}$ depending on the time at different points in the cross-section of the bar.

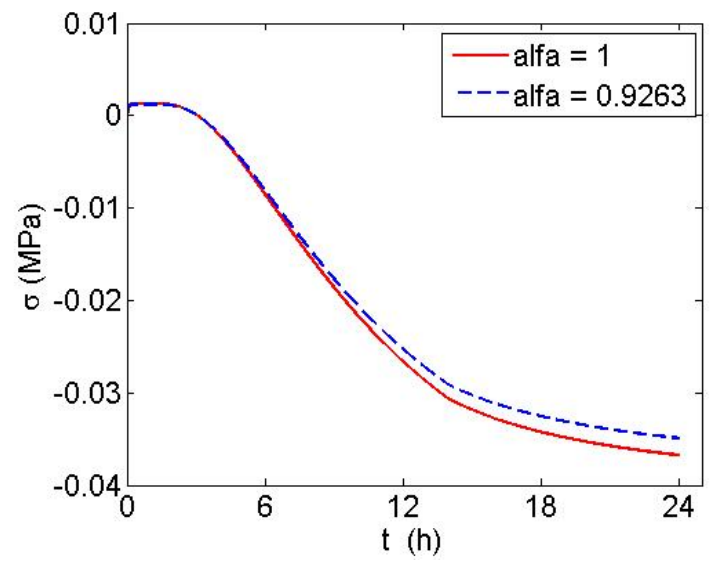

(a)

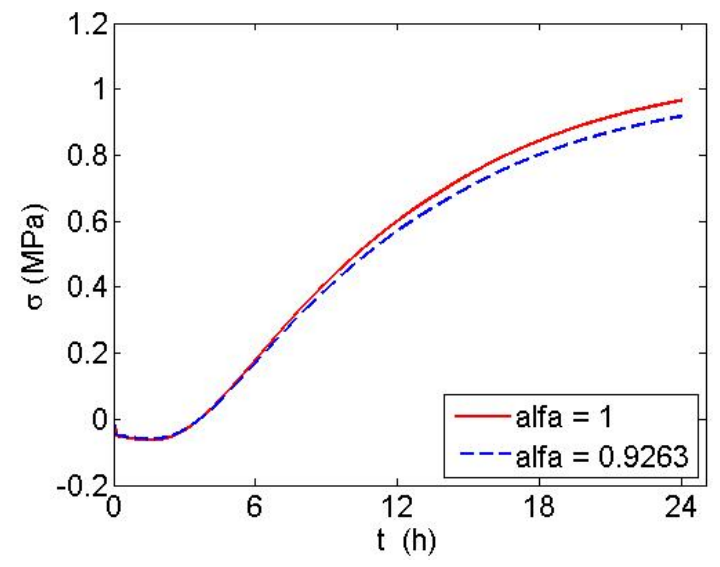

(b) 


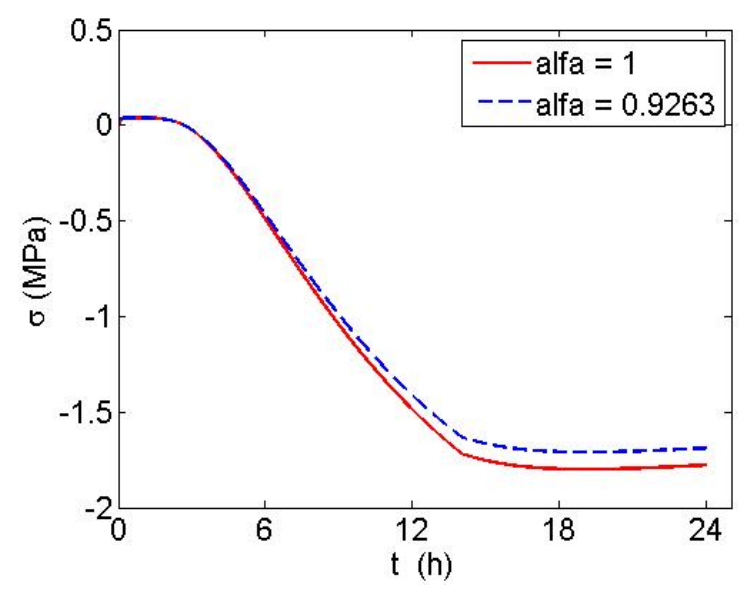

(c)

Figure 6. The value of stress components $\sigma_{22}$ depending on the time at different points in the cross-section of the bar: a) $A(0 ; 0)$; b) $B\left(l_{1} / 2 ; l_{2} / 2\right)$; c) $C\left(l_{1} ; l_{2}\right)$

Figure 7 shows the value of stress components $\sigma_{12}$ depending on the time at different points in the cross-section of the bar.

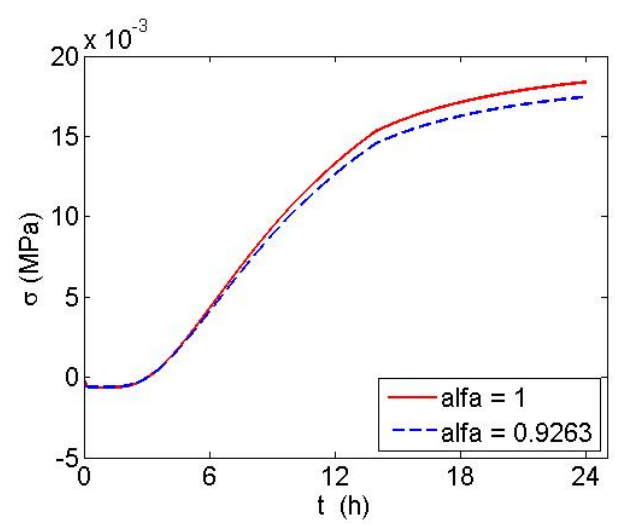

(a)

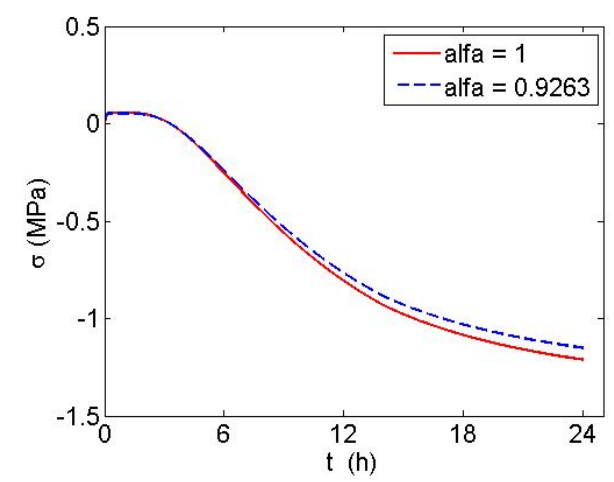

(b)

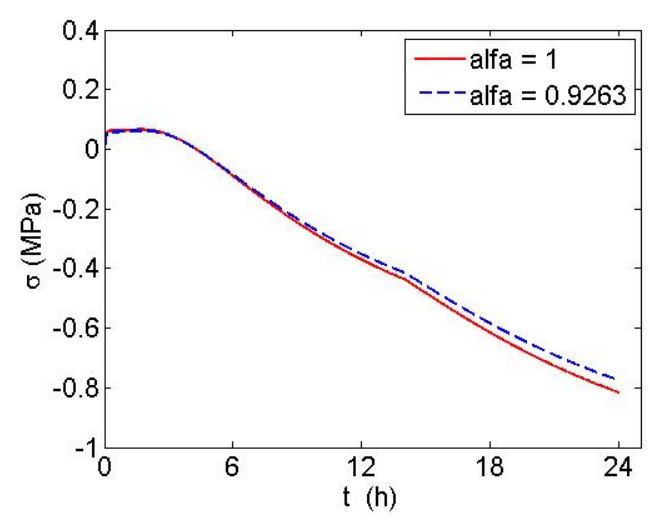

(c)

Figure 7. The value of stress components $\sigma_{12}$ depending on the time at different points in the cross-section of the bar: a) $A(0 ; 0)$; b) $B\left(l_{1} / 2 ; l_{2} / 2\right)$; c) $C\left(l_{1} ; l_{2}\right)$ 
Graphics in figures 5-7 draw us to the conclusion that the fractal materials obtain such property as "memory". In his works, Yu.N. Rabotnov has proposed to use fractional exponential function as the basis for approximation of wood relaxation function that is caused in its turn by the presence of the effect of "memory" in it.

For modelling heat and mass transfer in the wood drying process we use the system of differential equations with partial derivatives of fractional order and appropriate initial and boundary conditions taking into account certain parameters of drying chamber and the coefficients characterizing timber. The problem of deformation-relaxative state is described by a system of differential equations with partial derivatives of fractional order and appropriate initial and boundary conditions characterizing the rheological behavior of wood. Particularly, in this problem the relaxation function plays one of the key roles. It is defined as the resolvent of creep function, which in its turn is determined by the experimental data of the creep of wood.

For approximation of the creep of wood a linear combination of basic functions is used. In the traditional approach usually the exponential function is chosen for the base. In the process of investigating such rheological properties of wood as the effects of "memory", self-organization and blur relaxation spectrum were determined. Materials with these qualities are called materials with fractal structure. Due to that Yu.N. Rabotnov proposed to use fractional exponential function, later called Rabotnov's function to describe the creep of wood. This leads to using the mathematical tool of differential equations of fractional order in constructing mathematical models.

In this paper to describe the creep of wood we have taken into account fractional exponential Rabotnov's function. Approximating experimental creep data of different tree species we concluded that for softwood (linden, pine, aspen) the degree of fractality is higher than for hard wood (oak, larch, ash). We also compared the approximants constructed on the base of exponential and fractional exponential functions. With the same number of basic functions included into the approximant, the approximation error is essentially lower when fractional exponential functions are used than the bases in comparison with the exponential ones.

Having analyzed the results of non-isothermal moisture transfer problem in capillary-porous materials with fractal structure we came to the conclusion that using the mathematical tool of differential equations of fractional order such a phenomenon as subdiffusion $(0<\alpha<1)$ can be described. Index of fractional time derivative $\alpha$ meets fate channels (branches) open for the flow depicted at Figures 4-7.

Analyzing the curves of the components of stress, strain and displacement we can also conclude that the use of the mathematical tool of differential equations of fractional order allows us to describe the fractal properties of wood, such as the property of "memory".

\section{Conclusion}

Using the mathematical tool of differential equations of fractional order to simulate the heat and mass transfer process and the deformation-relaxative state in capillary-porous materials with fractal structure in comparison with traditional methods allows us to take into account the effect of "memory", blurring the relaxation spectrum, the complex nature of spatial correlations and effects of self-organization. The use of finite-difference methods allows to obtain adequate numerical values of simulated processes. Thus we can conclude that the use of the mathematical tool of differential equations of fractional order in comparison with traditional methods is more effective to describe the drying process of wood.

\section{References}

Baeumer, M., \& Kov'acs, M. M. (2007). Meerschaert, Fractional reproduction-dispersal equations and heavy tail dispersal kernels. Bull. Math. Biol., 69, 2281-2297. http://dx.doi.org/10.1007/s11538-007-9220-2

Beybalayev, V. D. (2009). Mathematical models of nonequilibrium processes in the environments with fractal structure: abstract of dissertation of candidate of sciences (Physics and Mathematics). Makhachkala, 18.

Iljushin, A. A., \& Pobedrja, B. E. (1970). Fundamentals of mathematical theory of thermovisco-elasticity. Moscow: 281.

Liu, F., Ahn, V., \& Turner, I. (2002). Numerical solution of the fractional advection-dispersion equation, Preprint.

Liu, F., Ahn, V., \& Turner, I. (2004). Numerical solution of the space fractional Fokker-Planck equation, J. Comput. Appl. Math., 166, 209-219.

Liu, F., Ahn, V., Turner, I., \& Zhuang, P. (2004). Numerical simulation for solute transport in fractal porous media. ANZIAM J., 45(E), C461-C473.

Lykov, A.V. (1968). The theory of drying. - M.: Energy, 472. 
Lynch, V. E., \& Carreras, B. A. (2003). D. del-Castillo-Negrete, K.M. Ferreira-Mejias, H.R. Hicks, Numerical methods for the solution of partial differential equations of fractional order. J. Comput. Phys., 192, 406-421. http://dx.doi.org/10.1016/j.jcp.2003.07.008

Meerschaert, M. M., \& Tadjeran, C. (2006). Finite difference approximations for two-sided space-fractional partial differential equations, Appl. Numer. Math., 56(1) 80-90. http://dx.doi.org/10.1016/j.apnum.2005.02.008

Meerschaert, M. M., Benson, D. A., \& Baeumer, B. (1999). Multidimensional advection and fractional dispersion. Phys. Rev. E 59, 5026-5028.

Meerschaert, M. M., Scheffler, H. P., \& Tadjeran, C. (2006). Finite difference methods for two-dimensional fractional dispersion equation. J. Comput. Phys., 211, 249-261. http://dx.doi.org/ 10.1016/j.jcp.2005.05.017.

Miller, K., \& Ross, B. (1993). An Introduction to the Fractional Calculus and Fractional Differential Equations, Wiley and Sons, New York.

Mohager, S., \& Toratti, T. (1993). Long term bending creep of wood in cyclic relative humidity. Wood Science and Technology, 27, 49-59.

Nigmatulin, R. R. (1992). Fractional integral and its physical interpretation. TMF, 3, 354-368.

Povstenko, Y. Z. (2005). Fractional heat conduction equation and associated thermal stress. Journal of Thermal Stresses, 28, 83-102. http://dx.doi.org/10.1080/014957390523741

Povstenko, Y. Z. (2005). Stresses exerted by a source of diffusion in a case of a non-parabolic diffusion equation. International Journal of Engineering Science, 43, 977-991. http://dx.doi.org/10.1016/j.ijengsci.2005.03.004

Povstenko, Y. Z. (2007). Two-dimensional axisymmetric stresses exerted by instantaneous pulses and sources of diffusion in an infinite space in a case of time-fractional diffusion equation. International Journal of Solids and Structures, 44, 2324-2348. http://dx.doi.org /10.1016/j.jjsolstr.2006.07.008

Salin, J. G., \& Ohman, G. (1998). Calculation of drying behaviour in different parts of timber stack. Proc 11th Int Drying Symp IDS 1998 Halkidiki Greece B: 1603-1610.

Samko, S. G., Kilbas, A. A., Marichev, O. I. (1987). Integrals and derivatives of fractional order and some of their applications. Minsk: Science and technology, $688 \mathrm{p}$.

Shubin, G. S. (1990). Drying and heat treatment of wood. M.: Forest Engineering, 336.

Sokolov, I. M., \& Klafter, J. (2005). From diffusion to anomalous diffusion: A century after Einstein's Brownian motion. Chaos, 15(2), 26-103.

Sokolovskyi, Ya. I., \& Bakalets, A. V. (2005). Modelling of nonlinear heat and mass transfer processes in the wood drying by finite element method. News of the National University "Lviv Polytechnic": Computer Sciences and Information Technologies, 543, 129-134. Lviv: National University "Lviv Polytechnic".

Sokolowskyi, Y., \& Shymanskyi, V. (2011). Fractal model of heat and mass transfer in capillary-porous materials. News of the National University "Lviv Polytechnic": Computer Sciences and Information Technologies, 694, 424-428. Lviv: National University "Lviv Polytechnic".

Sokolowskyi, Y., \& Shymanskyi, V. (2012). Mathematical model of heat-mass and deformation-relaxation state in capillary-porous materials with fractal structure // Physical and mathematical modelling and information technologies. No 16. - P. 133-142.

Zhang, Y., Benson, D. A., \& Meerschaert, M. M. (2003). H.P. Scheffler, On using random walks to solve the space-fractional advection-dispersion equations. J. Statist. Phys., 123, 89-110.

\section{Copyrights}

Copyright for this article is retained by the author(s), with first publication rights granted to the journal.

This is an open-access article distributed under the terms and conditions of the Creative Commons Attribution license (http://creativecommons.org/licenses/by/3.0/). 